\title{
Exploring information literacy through the lens of Activity Theory
}

\author{
Hazel Hall, Peter Cruickshank, and Bruce Ryan \\ Centre for Social Informatics, Edinburgh Napier University, Edinburgh, Scotland \\ \{h.hall, p.cruickshank, b.ryan\}@napier.ac.uk
}

\begin{abstract}
Activity Theory (AT) is presented as a framework for explaining Information Literacy (IL) as a technologically mediated social practice. This is achieved in the context of a study conducted in 2016 on the information gathering and sharing activities of Scottish community-level elected representatives. This work demonstrates the value of AT as (i) a tool for IL research that seeks to present information practices in their social contexts, and (ii) as a means of highlighting underlying issues within the social environment under review through the identification of contradictions within the activity system.
\end{abstract}

Keywords: Activity Theory, information literacy, hyperlocal democracy, libraries, lifelong learning.

\section{Introduction and Background}

The theme of this paper is Activity Theory (AT) as a framework for exploring Information Literacy (IL) as a technologically mediated social practice. The value of AT is discussed with reference to a research project entitled Information Literacy for Democratic Engagement (IL-DEM). IL-DEM was funded by the Information Literacy Group of the Chartered Institute of Library and Information Professionals in 2016 to investigate the ways in which community-level elected representatives (community councillors) in Scotland undertake two related information activities: (i) seeking and sharing the opinions of the citizens that they represent with higher tiers of government, and (ii) finding and sharing information from higher tiers of government with the citizens that they represent.

The main finding of the analysis presented below is that AT is an appropriate tool for IL research of this nature. Its main strengths are found in the processes of preparing data collection tools and the extraction of 'meaning' from interview data. In addition, AT is especially powerful at identifying contradictions between the activities under scrutiny in research projects. In this case, since IL was viewed through the lens of AT, barriers to information sharing, and the stimulation of change in information practice, came to the fore as strong themes in the findings of the empirical work. 


\subsection{Activity Theory}

$\mathrm{AT}$ is a framework that relates human activities to their social contexts. It provides a language for making sense of complex, real-world activities in cultural and historical contexts. As such, AT is not a predictive theory, but rather a tool that can be deployed with empirical data to develop understanding of the activities of actors [1].

AT developed from the work of Soviet psychologists such as Vygotsky [2], Rubenstein and Leont'ev [3]. They wished to understand human activities as systemic and socially-situated phenomena. A general account of AT's early history can be found in the work of Mironenko [3]. In Library and Information Science (LIS) research the application of AT in has been discussed more fully by Wilson [4].

One of the most frequently cited models of AT, and the one deployed in the study reported here, is that advocated by Engeström [5-7]. This version brings technology and context together into a unit of analysis called an 'activity system'. In Engeström's model subjects (people) use tools (which may be physical, e.g. technology, or cognitive, e.g. skills [7]) to attempt to achieve objects (or objectives). Subjects' activities spring from one or more motivations, that is, the reasons for attempting to achieve the objective(s) or goal(s) of the activity. Activities are constrained by social and/or workplace contexts $[1,4]$. Contexts comprise tools, the community (in AT terms, this may be may be the subject's immediate work group or team, or the wider organisational community, or society at large [4], that is, stakeholders in activities), the rules and norms of the community [8], and the division of labour around the activities [7]. The outcome (s) are distinct from the object(s) because they are the consequences of activity, and include unexpected results. It is also important to note that objects can change over time. For this reason Wilson introduced the concept of process within activity systems into his work on AT [4].

Issues within an activity system are explained through tensions and contradictions. These may be found: (i) within elements (e.g. tools, subjects); (ii) between elements (e.g. between a subject and a rule); (iii) between a central activity at one point in time and a central activity later on; and (iv) between activities [5]. AT also suggests that collaborative activities can be co-ordinated (participants work independently towards goals and using methods which they have not set), co-operative (participants set the common goals), or co-constructive (participants set the goals and methods) [9].

The language of activities, AT constructs, and contradictions hence provides a ready-built analytical framework for understanding underlying issues around any social activity. As such, AT has been used in studies of a number of workplace contexts, for example, use of mobile data by police [10], and in a variety of subject domains including LIS in general (as noted above), [7]. There are also examples of its prior use in IL research, [11]. However, to date, AT has not been deployed in research that considers IL in the context of 'hyperlocal' democracy - democracy 'pertaining to a town, village, single postcode or other small, geographically defined community' [12]. Hyperlocal is interesting in this IL context because it implies that physical/face-to-face information interactions and channel-shifting are inherent, as will be seen below. 


\subsection{Community Councils}

Prior to discussing the means by which IL can be explored through the lens of AT, it is worth providing some background information on the local context of the research study that served as the test site here.

Scotland's local government was subject to major reorganisation in 1975 [13]. Community councils were established as part of this process. Their creation was meant to address fears that citizens might feel remote from the democratic process due to the reduction in the number of local authorities in the new local government structure.

The regulation and support of community councils is currently delegated to Scotland's 32 local authorities. Local authorities are responsible for the 'definitions' of their community councils' areas and numbers of members, for running community council elections, and for providing much of their (somewhat meagre) funding. The 'definitions' are found in documents known as 'Schemes'. Most Schemes also state how community councils are run, and they provide examples of activities that they may undertake with reference to relevant legislation. Membership of any community council comprises voting members (elected and co-opted), and non-voting, ex-officio members (local authority councillors, members of the Scottish Parliament, and members of the UK Parliament whose wards and constituencies overlap the community council's area).

Unlike the vast majority of Europe's democratic systems, community councils are not bodies of government $[13,14]$. Although they are conceived in the legislation as representative bodies for particular geographic localities, they have no duties to deliver services, nor can they raise taxes. Each community council is set up to 'ascertain, coordinate and express to the local authorities for its area, and to public authorities, the views of the community which it represents, in relation to matters for which those authorities are responsible, and to take such action in the interests of that community as appears to it to be expedient and practicable' [15], so their role is explicitly centred on information. They also have a limited role in planning: they may comment on planning applications, such as from the change of use of a garage to an office in a conservation area, to large housing or industrial developments.

The community council system in Scotland faces a number of challenges. The main problem is that it relies almost entirely on the voluntary efforts of community councillors, and they have no funding for the hire of additional professional assistance [16]. As a result, many community councils struggle to fill their vacancies. Indeed in some parts of the country community councils do not exist at all [13, 17-20]. The demographic profile of the volunteer community councillor population is also an issue, particularly in terms of information literacy. Typically community councillors are older citizens who have not benefited from any formal information skills training over the course of their lifetime, whether at school or in the workplace. This means that few have developed adequate skills to deal with the tasks of gathering, processing and presenting information on their communities' views. This is reflected in the low numbers of community councils known to use the Internet to engage with, and/or obtain information from, their citizens [18-20].

Whereas the information practices in local government have previously been the subject of academic research [e.g 21,22], this study is significant as the first to have 
considered the information literacy of volunteers active in hyperlocal government.

\subsection{The IL-DEM Project: Motivation and Methods}

The main purpose of IL-DEM was to understand reasons for, and seek solutions to, some of the manifest problems outlined above. Community councils' low use of the Internet was one stimulus. It was also deemed important to examine other channels for information sharing such as face-to-face, letters, and telephone. This is because of the hyperlocal nature of the work of community councils. Contact can shift rapidly from one channel to another when information is shared within community councils. For example, a conversation might begin at a formal meeting or in a chance encounter, then may be continued via social media, and again at the next community council meeting.

Data were collected for IL-DEM through hour-long semi-structured interviews with community councillors $(n=19)$ between 21 November and 9 December 2016. The councillors were based in a various localities across Scotland. These ranged from areas with low to high deprivation, and remote rural to highly urban environments. The interviewees were asked to specify their age by decade. The breakdown was one interviewee in his/her 30s, three in their 40s, nine in their 50s, four in their 60s, and two in their 70s. The interviewees served on community councils in eight local authority areas: Aberdeen, Argyll and Bute, Edinburgh, Fife, Glasgow, Perth and Kinross, Renfrewshire, and Shetland

The interviewees responded to a call for participation in the project that was posted to an online discussion board for community councillors, and the national community council web site. Community council liaison officers, i.e. the local authority staff charged with supporting community councils, were also made aware of the project by email and through discussion board postings.

The interview questions were generated with reference to project research questions and dominant themes from a review of the literature. As well as prompting the interviewees to speak about information literacy in general, as well as their own information practices, the questions were designed to address other related topics such as lifelong learning, social capital and citizenship. The interview schedule was piloted with staff from the Improvement Service (the national improvement service for local government in Scotland) prior to implementation.

The AT constructs described in [1] and elements of the SCONUL 7-pillar model of information literacy were used both (i) to inform the development of the interview schedule, and (ii) to manually code the data following transcription of the interviews. The latter was achieved by listing the research questions and the AT constructs in the top row of a spreadsheet, with the interview questions in the left-hand column. Then relevant data from each interview were copied into the spreadsheet cells according to (i) interview question and (ii) research question or construct. Text-concatenation allowed for the assembly of all data thematically for analysis.

It should be emphasised that the focus of the discussion below is not the findings of IL-DEM per se, nor their articulation with the SCONUL pillars, but the deployment of AT in a research project concerned with IL. This is achieved with reference to two 
information activities undertaken by the community councillors interviewed: (i) their sharing information about citizens' opinions to higher authorities; and (ii) their sharing of information from higher authorities to citizens.

The main findings of the empirical work completed for IL-DEM on the practices of community representatives in exploiting information channels for citizen engagement, and their relationship with the SCONUL pillars, are found in the IL-DEM project report, and a paper presented at Information: interactions and impact (i3) 2017 [23, 24]. These relate that, despite the high level of education and self-efficacy of community councillors, their democratic activities are not fully underpinned by information practices in line with the SCONUL 7 pillars.

\section{Alignment of data from the IL-DEM project to AT Constructs}

Since the purpose of this paper is to explore the value of AT in IL research, the constructs of AT introduced above are reframed below with reference to data gathered for a project concerned with IL (IL-DEM). Some examples are also given of project findings that emerged from this process of deliberately considering the IL-DEM data through the lens of AT and its constructs. It should be noted, however, that these examples are for illustration only: the full project findings are found in other outputs that report the empirical study from the perspective of a contribution to the body of extant work in IL [23, 24].

\section{$2.1 \quad$ Subjects}

In some cases, the application of AT constructs to IL can be challenging. For example, an initial problem may be the definition of subjects following practice in AT. The particular challenge faced in the IL-DEM project was whether to treat individual community councillors as the subjects (on the basis that they are the people who are involved in the activity), or for this label to be assigned to the community councils as 'inanimate' groups of actors. Such a decision is important in studies of information behaviour and use, given that there may be a need for findings to be presented at the level of the individual, the group, or from both perspectives.

In partial resolution of this question, a decision was taken to treat individuals as 'interviewees', and community councils as collective subjects, in this work. This follows practice in other studies that have used AT in library and information science research. For example, in their study Detlor, Hupfer and Smith class libraries as subjects, having collected their data by interview with individuals [7].

\subsection{Motivations}

At the outset it was anticipated that community councillors would find it easy to report the reasons why they were motivated to undertake information activities in response to the requirements of the legislation for community councils, and the content of local authority Schemes. This proved to be the case: the majority of interviewees (14) 
provided data on their reasons for engaging in information activities that fitted with the motivation construct of AT. In addition, the interviewees explained the more general motivations to volunteer as a hyperlocal representative.

\subsection{Objects and Outcomes}

Interview questions about the information roles of community councils, and the extent to which they are successful in meeting the requirements of these, allowed for the activity system under review to be considered with reference to the AT constructs of objects (the goals that the subjects wish to achieve through their activities) and outcomes (the actual results of activities).

In line with the legislation, it was anticipated that the main object of community councillors' information activities would be to gather, process and convey information about their citizens' opinions. The analysis of the interview data using AT constructs confirmed this. For example, 15 interviewees recognised the importance of information sharing objects: one said 'We don't transact actions, we don't have any financial power. Our currency is information.'

The consideration of outcomes surfaced evidence of poor information practices within community councils. For example, two interviewees from the same community council admitted that its 'mailing list [includes] 60-odd people, which is nothing given that that there are 25,000 people in the area'. Another interviewee joined her community council specifically to make it share information with its community but, at the time of interview, she was considering resignation due to a lack of support from her colleagues.

\subsection{Tools}

In AT, tools are the physical or mental devices used by subjects in their activities. Interviewees were therefore asked about information sources and channels used to (i) gather information about local issues, and (ii) to share information with their citizens. This allowed for the identification of a range of tools including bodies (e.g. local authorities) and individuals (e.g. citizens by word of mouth) as information sources, as well as traditional media (e.g. local press) and Internet sources (e.g. Facebook). Commentary on the perceived usefulness of such tools, and the level of comfort that community councillors experience when using them, provided further data for interpretation when the full project findings were applied to the SCONUL model.

\subsection{Rules and norms}

Taking into account the AT construct of rules and norms, the regulations and conventions that mediate activities and relationships within the activity system under review were identified as part of the IL-DEM project. This brought to the fore the rules and norms imposed on community councils (the legislation and Schemes), as well as a number devised by community councillors themselves to improve information practices within their community councils. These included, for example, processes decided at local level to minimise information overload, such as only reviewing planning matters 
that impinge directly on the area covered by the community council. The consideration of the AT constructs of rules and norms in respect of information activities amongst this group was also useful in revealing the factors that influence the ways in which information tasks are undertaken by community councils, including whether or not they are undertaken at all.

\subsection{Community}

Prior to entering the field, of the types of communities (the AT terminology for stakeholder groups) that develop around the information activities of community councillors were already known: fellow community councillors; the citizens that they represent (especially those who engage with their community councils); and functionaries such as the local authority officials and councillors who interact with community councils. These were confirmed in the data collected and analysed, with additional commentary provided on levels of engagement across the communities.

\subsection{Division of labour}

Division of labour in AT refers to the manner(s) in which work is allocated among various actors in the activity [7]. For this reason interviewees were asked about taskallocation for information-related activities within their community councils. The data gathered provided detail on a range of approaches to task allocation e.g. according to individual skills, or designated community council roles, such as online communication. Thus AT was found to be useful in establishing an overview of the means by which information-related tasks are allocated in community councils.

A challenge of considering the IL-DEM data with reference to the construct of division of labour, however, was to take into account the extent to which it is mediated by rules and norms. In short, it proved difficult to find clear-cut distinctions between these two constructs.

\section{Discussion and Conclusions: the Value of Deploying Activity Theory in the IL-DEM Project}

Following the analysis of the full data set, with reference to AT constructs as described above, it was possible to portray the information activities and relationships of the subjects in the IL-DEM project in an activity diagram. This is shown below in Fig. 1. 
Tools

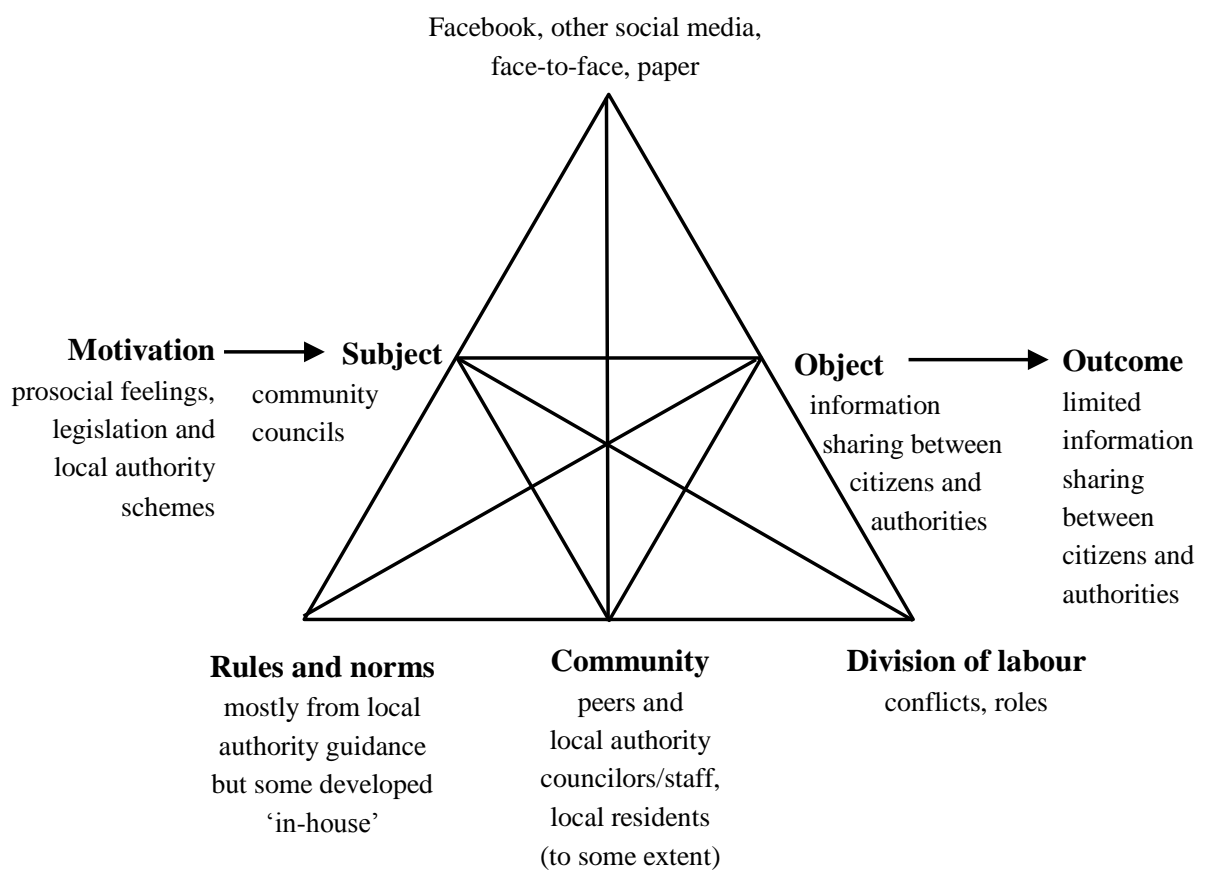

Fig. 1: Activity system for community councillor information activities

The use of AT in this project was valuable first because it allowed for the completion of the data collection and analysis processes in a systematic way. When preparing the main tool of data collection, for example, reference to the main AT constructs (as outlined above) ensured that relevant and useful interview data were collected: the simple process of checking that each of the constructs was 'covered' in the interview schedule ensured that it was comprehensive enough to extract the data required to answer the IL-DEM project research questions from the output of the interviews. Equally, AT furnished a ready-made framework for coding the project data to then generate an analysis of activities reported by the interviewees in the social context under review. In addition, having prepared the data in this way, it was possible to see alignments between the data categorised under the AT constructs and the SCONUL IL pillars. For example it was found that data relevant to both tools and community in AT fit with the gather and present pillars.

The second main benefit of deploying AT in this work was that it brought to the fore a number of important findings on the level of information literacy amongst community councillors in Scotland, and the factors that influence this - it was key to answering the core research questions of the IL-DEM project. Of particular interest here are the contradictions identified from the data set, not least because these can serve as the foundations of the future practical benefits of completing this work, by 'exposing opportunities for change' [7]. For example contradictions uncovered in the data set 
pointed to the status of community councillors as part-time volunteers who do not have time to undertake all possible information sharing activities. This helps explain community councils' low use of the Internet to engage with citizens.

A further benefit of using AT in this work was that it led to the generation of the project's three main recommendations: (i) community councillors should lobby for suitable training, and take part in an audit of their information skills and practices, with leadership and support from the Improvement Service; (ii) community council liaison officers should do more to emphasise the value of information skills in supporting community councils' statutory role of representing citizen opinions; and (iii) public library services should extend their roles to support community councils.

The deployment of AT in a project such as this, however, is not without its challenges. Some decisions on constructs are difficult to make, as illustrated above with reference to the question of subjects in the IL-DEM project. Similarly, here the distinctions between the constructs of the rules and norms and division of labour were not always clear. The definition of the activity system itself can also raise questions. In the case of Scottish community councils and information sharing for example, it could be argued that there are actually two activity systems in operation: one for information that is disseminated in one direction, and a second for the other.

Despite these challenges, this work has shown that AT is valuable to research design in projects concerned with group information practices. In addition, AT can contribute to the generation of findings that contribute to the development of existing models (in this case the SCONUL 7 pillars). Since activity diagrams provide a snapshot of the system under review at a certain time, a further benefit of deploying AT is in longitudinal studies where the impact of earlier interventions can be observed. This would be particularly interesting in the case of the Scottish community councils, should the recommendations summarised in the project report be implemented [23-24].

Acknowledgements. The authors are grateful to CILIP's Information Literacy Group for project funding, and to the community councillors who took part in the research.

\section{References}

1. Wilson, T.: A Re-examination of Information Seeking Behaviour in the Context of Activity Theory. Inf. Res. 11 (2006)

2. Vygotsky, L.S.: Mind and Society. Harvard University Press, Cambridge (1978)

3. Mironenko, I.A.: Concerning Interpretations of Activity Theory. Integr. Psychol. Behav. Sci. 47, 376-393 (2013)

4. Wilson, T.: Activity Theory and Information Seeking. Annu. Rev. Inf. Sci. Technol. 42, 119-161 (2008)

5. Engeström, Y.: Learning by Expanding: an Activity-Theoretical Approach to Developmental Research. Orienta-Konsultit, Helsinki (1987)

6. Allen, D., Karanasios, S., Slavova, M.: Working with Activity Theory: Context, Technology, and Information Behavior. J. Am. Soc. Inf. Sci. Technol. 62, 776-788 (2011)

7. Detlor, B., Hupfer, M.E., Smith, D.H.: Digital Storytelling and Memory Institutions: a Case Study Using Activity Theory. ASIST 2016 (2016)

8. Allen, D., Karanasios, S., Norman, A.: Information Sharing and Interoperability: the Case 
of Major Incident Management. Eur. J. Inf. Syst. 23, 418-432 (2014)

9. Bardram, J.E.: Collaboration, Coordination and Computer Support: an Activity Theoretical Approach to the Design of Computer Supported Cooperative Work. Aarhus University, Aarhus (1998)

10. Karanasios, S., Vardaxoglou, G., Allen, D.: Innovation in UK law Enforcement: the Emergence of Mobile Data. In: 15th Am. Conf. Inf. Syst. (AMCIS 2009). pp 1-10 (2009)

11. Abdallah, N.B.: Activity Theory as a Framework for Understanding Information Literacy. In: Kurbanoğlu, S., Grassia, E., Mizrachi, D., Catts, R., Špiranec, S. (eds): Worldw. Commonalities Challenges Inf. Lit. Res. Pract. Springer, Istanbul, pp. 93-99 (2013)

12. Radcliffe D.: Here and Now: UK Hyperlocal Media Today. http://www.nesta.org.uk/publications/here-and-now-uk-hyperlocal-media-today (2012)

13. Goodlad, R., Flint, J., Kearns, A., Keoghan, M., Paddison, R., Raco, M.: The Role and Effectiveness of Community Councils with Regard to Community Consultation. Scottish Office Central Research Unit, Edinburgh (1999)

14. Glasgow City Council: The Scheme for the Establishment of Community Councils. (2013)

15. UK Government: Local Government (Scotland) Act 1973. (1973)

16. Bort, E., Mcalpine, R., Morgan, G.: The Silent Crisis: Failure and Revival in Local Democracy in Scotland. Jimmy Reid Foundation, Glasgow (2012)

17. McIntosh, N., Alexander, A., Cubie, A., Leicester, G., Mackay, E., Millar, M., Smith, M., Watt, M.: The Report of the Commission on Local Government and the Scottish Parliament. Scottish Office, Edinburgh (1999)

18. Ryan, B.M., Cruickshank, P: Community Councils Online. Edinburgh Napier University, Edinburgh (2012)

19. Ryan, B.M., Cruickshank, P: Community Councils Online. Edinburgh Napier University, Edinburgh (2014)

20. Cruickshank, P., Ryan, B.M., Smith, C.F.: Disconnected Democracy? A Survey of Scottish Community Councils' Online Presences. Scottish Aff. (2014)

21. Wilson, T.D., Streatfield, D.R. \& Mullings, C.: Information needs in local authority social services departments: a second report on Project INISS. Journal of Documentation, 35(2), 120-136 (1979)

22. Wilson, T.D. \& Streatfield, D.R.:You can observe a lot ... A study of information use in local authority social services departments conducted by Project INISS, Postgraduate School of Librarianship and Information Science, University of Sheffield, Sheffield, (occasional publication no. 12). Available at: http://informationr.net/tdw/publ/INISS/ (1980)

23. Hall, H., Cruickshank, P., Ryan, B.M.: Information Literacy for Democratic Engagement. Edinburgh Napier University, Edinburgh. https://communityknectdotnet.files.wordpress.com/2017/02/il-dem-stakeholder-reportjanuary-2017.pdf (2017)

24. Cruickshank, P., Hall, H., Ryan, B.M.: Practices of Community Representatives in Exploiting Information Channels for Citizen Engagement. Paper presented at information: interactions and impact 2017, Aberdeen, 27-30 June 2017. Abstract available at: http://www.napier.ac.uk/research-and-innovation/research-search/outputs/practices-ofcommunity-representatives-in-exploiting-information-channels-for-citizen (2017) 